\title{
Occurrence of oriental fruit moth (Grapholita molesta) in apple orchards in New Zealand
}

\author{
P.L. Lo and J.T.S. Walker \\ The New Zealand Institute for Plant \& Food Research Limited, Private Bag 1401 \\ Havelock North 4157, New Zealand \\ Corresponding author: peter.lo@plantandfood.co.nz
}

\begin{abstract}
Grapholita molesta (Oriental Fruit Moth, OFM) primarily infests stonefruit, but overseas it has adapted to pipfruit and become a major pest of apples and pears in some places. The objective of this study was to determine the prevalence of OFM in New Zealand apple orchards. Pheromone trapping was conducted in five apple growing regions in 2014-15 and repeated in Hawke's Bay and Nelson in 2015-16. No OFM was found in Gisborne (three orchards), Nelson (six) or Central Otago (seven), but it was recorded on one of six Waikato orchards. In Hawke's Bay, OFM occurred on 23/36 orchards, although on 15 properties $\leq 7$ moths/trap/year were caught. However, traps in two orchards caught over 100 moths/year. The few OFM collected on some orchards may have been "strays" from nearby stonefruit orchards, but the high numbers in these two apple orchard blocks suggested the populations were established. The implications of OFM becoming an apple pest or reaching the South Island are discussed.
\end{abstract}

Keywords Grapholita molesta, oriental fruit moth, apple, New Zealand.

\section{INTRODUCTION}

Oriental fruit moth (OFM, Grapholita molesta) is primarily a pest of the Prunus genus (stonefruit), particularly peaches and nectarines, although apricots, cherries and plums are also hosts (Anon. 1999). Other hosts can include apple (Malus) and pear (Pyrus) when they are grown in proximity to peach orchards, while it has also been found on quince and almonds (Russell 1989). The larvae preferentially tunnel into fruit, but they will also bore into young shoots when fruit are not available or are small. This causes a characteristic die-back of the tips which can be the first sign of an OFM infestation.

OFM is thought to be native to central Asia from where humans have distributed it throughout stonefruit-growing areas of the world during the past century (Rothschild \& Vickers 1991). Adult OFM generally move short distances and most moths disperse less than $200 \mathrm{~m}$, although they are capable of flying over $2 \mathrm{~km}$ (Yetter \& Steiner 1932; Sziraki 1979). Hence, the natural rate of movement by OFM is slow. Its spread, however, is facilitated by the transport of infested material, either in fresh fruit and on nursery trees or in containers where mature larvae have left fruit and pupated. OFM now occurs in other parts of Asia, Europe, the Americas, North Africa, Middle East and Australasia.

OFM was first recorded in New Zealand in south Auckland in 1976 (Cox \& Dale 1977), although subsequent pheromone trapping revealed that it was already widely established in the Auckland area (Baker 1982). Two years later, OFM was recorded from Whangarei to the Bay of Plenty, and by 1982 
it had spread northwards to Kaitaia and south as far as Gisborne and Hawke's Bay (Baker 1982). OFM is now presumed to be found throughout the North Island, although Lo (2000) observed that 18 years after it was first found in Hawke's Bay, half the stonefruit orchards surveyed were still free of this pest. A 20-year trapping programme in Central Otago in the South Island caught only one OFM in 1992, but there were no signs of an established population and no further moths were trapped up to 2000 (McLaren \& Wearing 2000).

In the 1990s, OFM adapted to pipfruit and became a key pest of apples and pears in Australia (Il'ichev et al. 1998) and the USA (Kovanci et al. 2005). Following the discovery of OFM in 2002 in Quebec, Canada, it was later found on 10/24 apple orchards there between 2003 and 2005 (Bellerose et al. 2007). In New Zealand, OFM has been recorded from apples in Auckland (Baker 1982), while Waikato has a small area of commercial apple production and several orchards were known to have been infested with this pest in the past (S. June, formerly Pickmee Fruit Company, personal communication).

The New Zealand pipfruit industry occupies about five times the planted area of stonefruit, and almost two thirds of it is in the North Island (Anon. 2015). It has been a concern that OFM could become more widespread and abundant on apples. This could necessitate additional costs to producers for OFM-specific control measures. In addition, OFM larvae and its damage could be mis-identified for codling moth (Cydia pomonella) larvae and damage.

This study was initiated after an orchardist in Gisborne reported unusual insect damage to the shoot tips of some young apple trees in autumn 2014. Shoot samples were sent to Plant \& Food Research in Havelock North, where several larvae were found and identified as being OFM. The trees in Gisborne had come from a nursery in Hawke's Bay that had also sent the same cultivar of trees to Nelson. The sale of potentially OFM-infested nursery stock to growers in Nelson was of concern because the South Island of New Zealand is believed to be free of OFM. The objective of this study was to determine how widespread
OFM is on New Zealand apple orchards.

\section{METHODS}

Apple orchards were monitored for OFM in Waikato, Gisborne, Hawke's Bay, Nelson and Central Otago in 2014-15. Monitoring of OFM was repeated in Hawke's Bay and Nelson in 2015-16. Pheromone traps were sent to the Waikato orchards known to have had OFM previously. Monitoring was also conducted in Gisborne at the orchards where the young OFM-infested trees were located. Hawke's Bay is the main apple-producing region of New Zealand and also home to the second largest area of stonefruit. Therefore, the most intensive monitoring of apple orchards was conducted in this region. Monitoring included two orchards that supplied budwood to the nursery whose trees were the source of the Gisborne infestation. Budwood collected from infested orchards is the likely path for OFM infestation of nursery seedling trees. Nelson in the South Island is the other major apple-growing region, and all the orchards that received the same batch of seedling trees as Gisborne were monitored for OFM. The fifth region was Central Otago, which has New Zealand's largest area of stonefruit.

In each orchard, usually one but occasionally two Delta traps with a rubber septa pheromone lure (International Pheromone Systems Ltd) on a sticky base were placed in orchards in December or January and checked approximately weekly. Hawke's Bay orchards were monitored until April each year. In other regions, the trapping period varied from 6 to 11 weeks. OFM has three to four generations in New Zealand (Russell 1987), with peaks of adult emergence from September to March (Russell 1982). The number of orchards monitored is shown in Table 1.

In March and April 2016, apples from commercial orchards in Hawke's Bay that showed larval tunnelling damage were collected as part of other research on codling moth. The apples were cut open to look for larvae, which were either 
Table 1 Number of New Zealand apple orchards monitored for oriental fruit moth in five regions with pheromone traps and the numbers of moths caught.

\begin{tabular}{lcccccc}
\hline Region & Year & No. orchards & \multicolumn{3}{c}{ Number of oriental fruit moth/trap/year } \\
\cline { 3 - 6 } & & monitored & 0 & $1-7$ & $9-20$ & $60-170$ \\
\hline Waikato & $2014-15$ & 6 & 5 & 0 & 1 & 0 \\
Gisborne & $2014-15$ & 3 & 3 & - & - & - \\
Hawke's Bay & $2014-15$ & 20 & 6 & 11 & 2 & 1 \\
& $2015-16$ & 28 & 11 & 15 & 0 & 2 \\
& Overall & 36 & 13 & 20 & 1 & 2 \\
Nelson & $2014-15$ & 4 & 4 & - & - & - \\
& $2015-16$ & 2 & 2 & - & - & - \\
Central Otago & Overall & 6 & 6 & - & - & - \\
\hline
\end{tabular}

examined with a microscope or placed in test tubes with artificial diet to be reared. Some of these larvae were OFM and these data are presented here. Larval OFM and codling moth are similar in appearance. The key distinguishing feature is that the former has an anal comb that protrudes from under the last abdominal segment (Anon. 1999).

\section{RESULTS}

No OFM were found in Gisborne, Nelson or Central Otago, but it was recorded in Waikato and Hawke's Bay (Table 1). In the sole Waikato orchard where OFM was found, 13 moths were trapped. This orchard also has stonefruit, which were a potential source of infestation. In Hawke's Bay, OFM occurred on 23 (64\%) of the orchards surveyed, although fewer than eight moths were trapped per season on 20 of these properties. Substantial numbers of moths were caught on three $(8 \%)$ of the surveyed orchards, including two that trapped over 100 moths/trap/year.

Approximately 100 larvae were collected from damaged apples, and at the date of publication, three were OFM. The remainder were either codling moth or are still being reared to adults.

\section{DISCUSSION}

There was no sign of established OFM populations on the seven orchards in Gisborne and Nelson that planted potentially infested nursery trees from Hawke's Bay. It is likely that either the trees were not infested, or the regular insecticide programme against codling moth and leafrollers has controlled any OFM infestations. This was a particularly good outcome for the stonefruit industry. South Island stonefruit growers have "area of freedom" status for OFM, which allows exports of fruit to Australia without the need for additional controls or inspections for OFM. This status would be withdrawn if OFM were to be found in the South Island.

Measures were taken at the time of OFM's arrival in New Zealand to restrict its movement within the country. For example, nurserymen in the North Island were asked to voluntarily dip the roots of Prunus trees in insecticide before they were sent to the South Island (McLaren \& Wearing 2000). Nurserymen and growers were reminded about good practices some years later (Lo 2000). It would be desirable for the industry to reinforce the ongoing necessity of these protective measures, in view of the volume and value of stonefruit exports to Australia. No other preventative measures such as limiting the inter-island transport of fruit were implemented.

The proportion of apple orchards in Hawke's Bay where OFM was found was higher than expected, given that adults do not fly far (Yetter \& Steiner 1932; Sziraki 1979). Pipfruit orchards often have blocks of stonefruit trees nearby, and many 
of the latter will be infested by OFM. The majority of the orchards in this survey had low numbers of OFM and some may well have been "strays". Nevertheless, the high number of OFM on two orchards, only one of which has stonefruit nearby, was more indicative of established populations. It is a concern for New Zealand orchardists that OFM may adapt to pipfruit and become a significant pest, which has happened overseas (Il'ichev et al. 1998; Kovanci et al. 2005; Bellerose et al. 2007).

A few OFM larvae were found in fruit that had received an export insecticide spray programme for codling moth and leafrollers. One of the consequences for apple growers of OFM becoming established in pipfruit is that the larvae and their tunnelling damage could be mistaken for those of codling moth. Accurate differentiation of OFM larvae from codling moth larvae requires expertise and appropriate microscopic magnification. OFM and codling moth damage to apples is indistinguishable. High value Asian export markets have a nil tolerance for codling moth in apple consignments (Anon. 2014). Growers targeting fruit for such destinations would be forced to send their crops elsewhere if codling moth damage or larvae were to be found. The potential loss of earnings is significant, especially if a consignment was wrongly withdrawn because of misidentification of OFM.

Another consequence is that OFM may require a specific pesticide control programme as the one for codling moth may not be suitable. In New Zealand, codling moth has one generation and a partial second with a prolonged emergence period that peaks in late December or January (Wearing \& Walker 1998). By comparison, OFM has three to four generations that would need to be controlled (Russell 1987). In Hawke's Bay, most of the stonefruit crop is harvested by March and growers have stopped their insecticide sprays for OFM before the last generation of moths appears. The bulk of the apple crop is picked between February and April, and therefore during this period there is a high probability of apple orchard infestation by OFM.

Overseas experience shows that OFM has the potential to become a major pest of apples in New Zealand. It would be prudent for OFM to be monitored more closely and controlled where necessary with pesticides or pheromone mating disruption. This applies especially on pipfruit orchards with known infestations, or those that are close to infested stonefruit blocks. A more targeted control programme on the few apple orchards where OFM is established may prevent or delay it from becoming a major pest of pipfruit.

\section{ACKNOWLEDGEMENTS}

We thank the many growers who allowed us to put pheromone traps on their orchards. Bernie Attfield, Lyn Cole, Jess Devitt, Tim Egan, Selwyn June, Anne Lister, Peter Shaw, Tara Taylor and Roger Wallis helped to check the traps. This research was supported by funding from Plant \& Food Research Core programme P/321041/02.

\section{REFERENCES}

Anonymous 1999. Oriental fruit moth Grapholita molesta. In: Integrated Pest Management for Stone fruits. University of California Division of Agriculture and Natural Resources Publication 3389, Oakland, USA.

Anonymous 2014. Ministry for Primary Industries Phytosanitary Official Assurance Programme for verification of the on-orchard pest management measures for codling moth (Cydia pomonella) 2013-2014. http:// www.biosecurity.govt.nz/files/regs/exports/ plants/compliance/codling-moth-sensitivemarkets-programme.pdf

Anonymous 2015. Fresh Facts New Zealand Horticulture 2015. Plant \& Food Research, $36 \mathrm{pp}$.

Baker RT 1982. Oriental fruit moth in New Zealand. Proceedings of the 35th New Zealand Weed and Pest Control Conference: 17-21.

Bellerose S, Chouinard G, Roy M 2007. Occurrence of Grapholita molesta (Lepidoptera: Tortricidae) in major applegrowing areas of southern Quebec. The Canadian Entomologist 139: 292-295.

Cox JM, Dale PS 1977. New records of plant pests in New Zealand. II New Zealand Journal of 
Agricultural Research 20: 109-111.

Il'ichev AL, Jerie PH, Hossain MS 1998. Wide area mating disruption of oriental fruit moth Grapholita molesta Busck (Lepidoptera: Tortricidae) in Victoria. In: Pest management - future challenges. Zalucki MP, Drew RAI, White GG eds. The University of Queensland, Brisbane, Australia. Pp 348-355.

Kovanci OB, Schal C, Walgenbach JF, Kennedy GG 2005. Comparison of mating disruption with pesticides for management of oriental fruit moth (Lepidoptera: Tortricidae) in North Carolina apple orchards. Journal of Economic Entomology 98: 1248-1258.

Lo P 2000. Oriental fruit moth - let's keep it out of the South Island. The Orchardist of New Zealand 73: 8 .

McLaren GF, Wearing CH 2000. Trapping for oriental fruit moth in Central Otago 19802000. HortResearch client report 2000-268, $2 \mathrm{p}$.

Russell DA 1982. Ecology of the oriental fruit moth, Grapholita molesta (Busck) in New Zealand. PhD thesis, University of Auckland.

Russell DA 1987. Parasitism of the oriental fruit moth Grapholita molesta (Lepidoptera: Tortricidae): The New Zealand position in a world perspective. New Zealand Entomologist 10: 13-26.
Russell DA 1989. Cydia molesta (Busck), oriental fruit moth (Lepidoptera: Tortricidae). In: Cameron PJ, Hill RL, Bain J, Thomas WP eds. A review of biological control of invertebrate pests and weeds in New Zealand 1874-1987. CAB Oxford, UK. Pp. 155-159.

Rothschild GHL, Vickers RA 1991. Biology, ecology and control of the oriental fruit moth. In: Geest LPS, van der Evenhuis $\mathrm{HH}$ eds. Tortricid pests: Their biology, natural enemies and control. Elsevier, Amsterdam, Netherlands. Pp. 389-412.

Sziraki G 1979. Dispersion and movement activity of the oriental fruit moth (Grapholita molesta Busck) in large scale orchards. Acta Phytopathologica Academiae Scientiarum Hungaricae 14: 209-228.

Yetter WP, Steiner LF 1932. Efficiency of bait traps for the oriental fruit moth as indicated by the release and capture of marked adults. Journal of Economic Entomology 25: 106116.

Wearing CH, Walker JTS 1998. Further data relating to the risk of codling moth on harvested apples in New Zealand. HortResearch Client Report 98/46. 